\title{
Radiation enhances the therapeutic effect of Banoxantrone in hypoxic tumour cells with elevated levels of nitric oxide synthase
}

\author{
MANAL MEHIBEL $^{1 *}$, SIMENDRA SINGH $^{1,2 *}$, RACHEL L. COWEN $^{1}$, KAYE J. WILLIAMS $^{3}$ and IAN J. STRATFORD ${ }^{1}$ \\ ${ }^{1}$ Experimental Oncology Group, Manchester Pharmacy School, University of Manchester, Manchester, UK; \\ ${ }^{2}$ School of Engineering and Technology, Sharda University, Greater Noida, India; ${ }^{3}$ Hypoxia and Therapeutics Group, \\ Manchester Pharmacy School, University of Manchester, Manchester, UK
}

Received September 4, 2015; Accepted October 16, 2015

DOI: $10.3892 /$ or.2016.4555

\begin{abstract}
Banoxantrone (AQ4N) is a prototype hypoxia selective cytotoxin that is activated by haem containing reductases such as inducible nitric oxide synthase (iNOS). In the present study, we evaluate whether elevated levels of iNOS in human tumour cells will improve their sensitivity to AQ4N. Further, we examine the potential of radiation to increase cellular toxicity of AQ4N under normoxic (aerobic) and hypoxic conditions. We employed an expression vector containing the cDNA for human iNOS to transfect human fibrosarcoma HT1080 tumour cells. Alternatively, parental cells were exposed to a cytokine cocktail to induce iNOS gene expression and enzymatic activity. The cells were then treated with AQ4N alone and in combination with radiation in the presence or absence of the iNOS inhibitor N-methyl-L-arginine. In parental cells, AQ4N showed little difference in toxicity under hypoxic verses normoxic conditions. Notably, cells with upregulated iNOS activity showed a significant increase in sensitivity to AQ4N, but only under conditions of reduced oxygenation. When these cells were exposed to the combination of AQ4N and radiation, there was much greater cell killing than that observed with either modality alone. In the clinical development of hypoxia selective cytotoxins it is likely they will be used in combination with radiotherapy. In the present study, we demonstrated that AQ4N can selectively kill hypoxic cells
\end{abstract}

Correspondence to: Dr Manal Mehibel, Experimental Oncology Group, School of Pharmacy and Pharmaceutical Sciences, University of Manchester, Oxford Road, Manchester M13 9PT, UK

E-mail: manal.mehibel@manchester.ac.uk

*Contributed equally

Abbreviations: CYPs, cytochromes; IFN- $\gamma$, interferon- $\gamma$; iNOS, inducible nitric oxide synthase; IRF-1, interferon regulatory factor-1; LPS, lipopolysccharides; NMLA, N-methyl-L-arginine; NO, nitric oxide; NOS, nitric oxide synthase

Key words: radiation, iNOS, nitric oxide, AQ4N, hypoxia via an iNOS-dependent mechanism. This hypoxia-selective effect can be augmented by combining AQ4N with radiation without increasing cytotoxicity to well-oxygenated tissues. Collectively, these results suggest that targeting hypoxic tumours with high levels of iNOS with a combination of AQ4N and radiotherapy could be a useful clinical therapeutic strategy.

\section{Introduction}

Hypoxia is present in the majority of primary and secondary solid human tumours and occurs as a consequence of the rapid tumour growth and the poorly organised vasculature (1). Tumour hypoxia represents a significant clinical problem since it increases resistance to radiotherapy and many conventional chemotherapeutic agents, in addition to promoting malignant progression and formation of metastases $(2,3)$. Notably, these hypoxic regions are a unique feature of solid tumours that does not occur in normal tissues and thereby, they are potentially exploitable in the development of cancer-specific therapies. This has led to the development of bioreductive drugs that are preferentially toxic to the hypoxic cells known as the "hypoxiaactivated prodrugs'. Agents currently under investigation include the dinitrobenzamide mustard drug PR-104 (Proacta), the nitroimidazole drug TH-302 (Threshold Pharmaceuticals), the dinitroazetidine compounds (4) and the lead hypoxiaselective Tirapazamine Analogue SN30000 (5).

A further class of hypoxia-activated prodrugs is exemplified by Banoxantrone (AQ4N), which is an aliphatic $N$-oxide (AstraZeneca) and its recently developed analogue OCT1002 (OncoTherics) (6). AQ4N exhibits minimal toxicity in normoxic cells but under hypoxic conditions, the drug undergoes two sequential $2 \mathrm{e}^{-}$reductions, via the mono $\mathrm{N}$-oxide AQ4M, to give the toxic metabolite AQ4 (7). The latter is a stable, potent topoisomerase II inhibitor and DNA intercalator. It is also unaffected by tumour reoxygenation, does not undergo futile cycling and has been shown to be efficient in exerting bystander cell killing (8).

AQ4N is well-documented in murine and human pre-clinical models as a very effective enhancer of radiotherapy $(9,10)$, chemo(cisplatin)-radiotherapy (10) and cyclophosphamide 
chemotherapies (11). Although hypoxia is a pre-requisite, enzymatic reduction is the key process controlling the activation and toxicity of AQ4N (12). Cytochrome P450 enzymes are important activators of the prodrug, leading to enhanced response of tumours to AQ4N $(13,14)$. Unfortunately, the levels of these enzymes can vary considerably within tumours (15). Recently, we and other researchers have made the observation that an alternative oxygen-dependent enzyme, known as inducible nitric oxide synthase (iNOS) is an efficient activator of $\operatorname{AQ4N}(8,16)$.

iNOS is commonly overexpressed in tumours compared to normal tissues and its expression levels have been linked to tumour grade (17-19), making it a potential biomarker for targeted therapies. The enzyme is a homodimer protein in which each monomer contains an oxygenase domain at its amino-terminal and a reductase domain at its carboxyterminal end (20). The iNOS reductase domain shares considerable homology with NADPH: cytochrome P450 reductase (21), whereas the oxygenase domain is responsible for the conversion of L-arginine to citrulline with the release of nitric oxide (NO) in the presence of oxygen (22). NO has direct cytotoxic properties and its role as an efficient radiosensitiser is well-established $(23,24)$.

The purpose of the present study was to investigate the potential of exploiting the dual role of iNOS as a prodrug activator and NO generator in enhancing tumour response to anticancer therapies. This was achieved by assessing the in vitro toxicity of $\mathrm{AQ} 4 \mathrm{~N}$ alone or combined with radiation in cell lines with variable levels of iNOS activity.

\section{Materials and methods}

Chemicals and gases. Mixtures of varying oxygen concentrations balanced with nitrogen $/ 5 \% \mathrm{CO}_{2}$ were purchased from the British Oxygen Company (London, UK). (AQ4N, 1,4-Bis-\{[2-(dimethylamino- $N$-oxide)ethyl)amino-5,8-dihydroxyanthracene-9,10-dione)\} was kindly provided by AstraZeneca (formally KuDOS Pharmaceuticals Ltd., Cambridge, UK). Recombinant murine interferon- $\gamma$ (IFN- $\gamma$ ) was purchased from R\&D Systems (Abingdon, UK). All other reagents were of analytical grade and were purchased from Sigma Chemical Co. (Poole, Dorset, UK).

Cell culture. Human fibrosarcoma HT1080 cells were obtained from the European Collection of Animal Cell Cultures (ECACC; Salisbury, UK). Cells were routinely cultured in RPMI-1640 medium supplemented with $2 \mathrm{mM}$ L-glutamine (both from Gibco, Paisley, UK) and 10\% fetal calf serum (LabTech International, Ringmer, UK). Puromycin-resistant iNOS clones were cultured under identical conditions in the presence of puromycin $(2.5 \mu \mathrm{g} / \mathrm{ml})$ and $100 \mu \mathrm{M} \mathrm{N}$-methyl-Larginine (NMLA). The cells were incubated under normoxic $\left(21 \% \mathrm{O}_{2}\right)$ conditions at $37^{\circ} \mathrm{C}$ in a humidified atmosphere of 95\% air: 5\% $\mathrm{CO}_{2}$. Anoxic incubations were carried out at $<0.01 \% \mathrm{O}_{2}$ in a catalyst induced hypoxic environment (Bactron Anaerobic Chamber, Sheldon Manufacturing, Inc., Cornelius, OR, USA). Hypoxic $\left(0.1\right.$ and $\left.1 \% \mathrm{O}_{2}\right)$ exposures were achieved by placing cells in sealed containers and flowing the appropriate gas mixture $\left(0.1\right.$ or $1 \% \mathrm{O}_{2}$, plus $5 \% \mathrm{CO}_{2}$ in $\left.\mathrm{N}_{2}\right)$ for up to $24 \mathrm{~h}$.
Generation of stable HT1080 cells overexpressing iNOS. The mammalian expression vector, pEF iNOS12-puro containing the iNOS and puromycin resistant genes was constructed and transfected into HT1080 parental cells, as previously described (25). The stability of transfected clones was frequently monitored by growing cells in the presence of puromycin $(2.5 \mu \mathrm{g} / \mathrm{ml})$ and checking the iNOS reductase and oxygenase activities.

Induction of iNOS expression using cytokines. Exponentially growing cells were harvested, seeded into $10 \mathrm{~cm}$ dishes (Falcon, Becton-Dickinson), and incubated for $24 \mathrm{~h}$. Cells were then exposed to the combination of IFN- $\gamma(100 \mathrm{ng} / \mathrm{ml})$ and LPS $(50 \mu \mathrm{g} / \mathrm{ml})$ in serum-free medium for $24 \mathrm{~h}$. After treatment, LPS and IFN- $\gamma$ were washed out from cultures, and serum was returned into the medium.

Measurements of iNOS oxygenase and reductase activity. Determination of enzymatic activity was made in cell lysates prepared from exponentially growing cultures. The oxygenase activity of iNOS was measured by monitoring the conversion of $\mathrm{L}-\left[\mathrm{U}-{ }^{14} \mathrm{C}\right.$ ) arginine to $\mathrm{L}-\left[\mathrm{U}-{ }^{14} \mathrm{C}\right.$ ) citrulline under fully aerobic conditions (25).

The iNOS reductase activity was determined by the NADPH-dependent reduction of cytochrome $c$, as previously described $(26,27)$.

Protein determination. The amount of total protein in the cell lysates was determined by the Pierce bicinchoninic acid (BCA) assay (28) using bovine serum albumin as a protein standard.

Drug sensitivity studies. Cells with or without prior treatment with cytokines for $24 \mathrm{~h}$ were washed in phosphate-buffered saline (PBS), harvested and seeded at different densities (500-5x $10^{4}$ cells) into $6 \mathrm{~cm}$ dishes (Falcon, Becton-Dickinson). Cells were then exposed to different oxygen conditions (normoxia, $1 \%$ oxygen, $0.1 \%$ oxygen or anoxia) for $24 \mathrm{~h}$ before treatment with AQ4N for $90 \mathrm{~min}$. After treatment, the cells were washed and fresh medium containing $100 \mu \mathrm{M}$ of the iNOS inhibitor NMLA was added. Survival was measured by colony formation assay 8-10 days later and individual colonies containing $>50$ cells were scored. Clonogenic survival was calculated for each drug dose after correcting for plating efficiency and values of $\mathrm{IC}_{10}$, the concentration of the drug required to result in $10 \%$ survival, were calculated from clonogenic survival curves.

AQ4N-radiation combination studies. Cells with or without prior treatment with cytokines were seeded and exposed to the different oxygen concentrations as described above. The cells were then treated with varying concentrations of AQ4N in the presence or absence of NMLA and X-ray was delivered at $0.75 \mathrm{~Gy} / \mathrm{min}$. The cells were then washed and fresh medium containing NMLA was added. Survival was measured by colony formation assay 8-10 days later. The sensitizer enhancement ratio (SER) for radiation was calculated by dividing the AQ4N dose that gives a surviving fraction of $0.1\left(\mathrm{IC}_{10}\right)$ for unirradiated cells by the AQ4N dose for cells treated with AQ4N plus radiation. The contribution of NO to the SER was calculated by dividing 
A

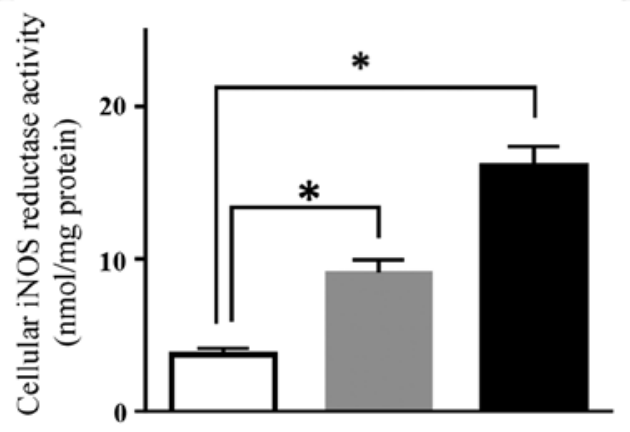

$\mathrm{B}$

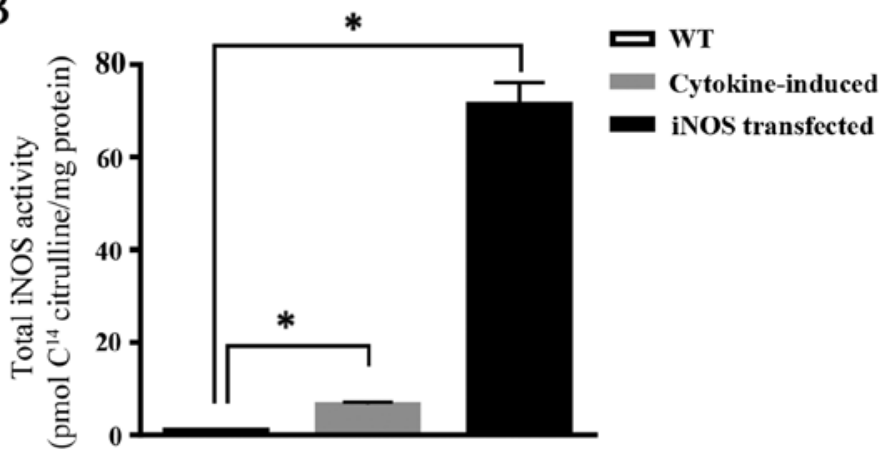

Figure 1. iNOS enzymatic activity. (A) Cellular iNOS reductase activity and (B) iNOS oxygenase activity in parental (口), cytokine stimulated (LPS and IFN- $\gamma$ )

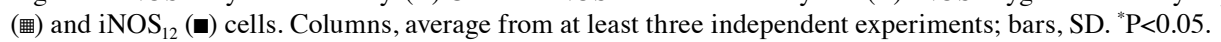

the $\mathrm{IC}_{10}$ for $\mathrm{AQ} 4 \mathrm{~N}$ for irradiated cells in presence of NMLA by the $\mathrm{IC}_{10}$ for $\mathrm{AQ} 4 \mathrm{~N}$ obtained in the absence of NMLA.

Statistical analysis. All data shown are from at least three independent experiments. Drug and radiation survival curves were plotted after correction for the plating efficiency of untreated cells. Statistical analysis was carried out with unpaired two-tailed t-tests and a P-value $\leq 0.05$ was considered to indicate a statistically significant result.

\section{Results}

Upregulation of iNOS activity in human tumour cells. We have employed an expression vector containing the cDNA for human iNOS to transfect HT1080 tumour cells. A clone $\left(\mathrm{NOS}_{12}\right)$ was selected based on stable expression of high iNOS activity as determined by the conversion of ${ }^{14} \mathrm{C}$-L-arginine to citrulline $(71.39 \mathrm{pmol} / \mathrm{min} / \mathrm{mg}$ compared to $0.94 \mathrm{pmol} / \mathrm{min} / \mathrm{mg}$ for parental cells). Catalytic activity of the reductase domain as determined by the NADPHdependent reduction of cytochrome $c$ was also elevated (16.12 $\mathrm{nmol} / \mathrm{min} / \mathrm{mg}$ in $\mathrm{HT} 1080-\mathrm{NOS}_{12}$ compared to $3.71 \mathrm{nmol} / \mathrm{min} / \mathrm{mg}$ for parental cells).

Induction of the iNOS protein using a cocktail of cytokines resulted in significant increase in enzymatic activity with a 2.5- and 7-fold increase in reductase and oxygenase activities, respectively, when compared to parental cells (Fig. 1).

Induction of the iNOS oxygenase activity reflects an enhanced potential for generating NO and as previously shown, NO production is oxygen-dependent (24) and this provides the basis for carrying out the subsequent drug/radiation experiments at different oxygen tensions.

Exposure of the cells to the cytokine cocktail did not affect the activity of cytochrome $\mathrm{P} 450$ reductase as shown in Fig. 2. This, therefore, discounts the possibility of additional contribution of $\mathrm{P} 450$ reductase to drug activation following treatment with cytokines.

Increased iNOS activity selectively enhances the cellular toxicity of AQ4N in hypoxia. Toxicity of AQ4N to HT1080 parental and cytokine-induced cells, and the $\mathrm{iNOS}_{12}$ clone was determined by exposing the cells to the drug for 90 min under different oxygen conditions (normoxia, 1 and $0.1 \%$ hypoxia and anoxia). At this stage, the cells were cultured in medium

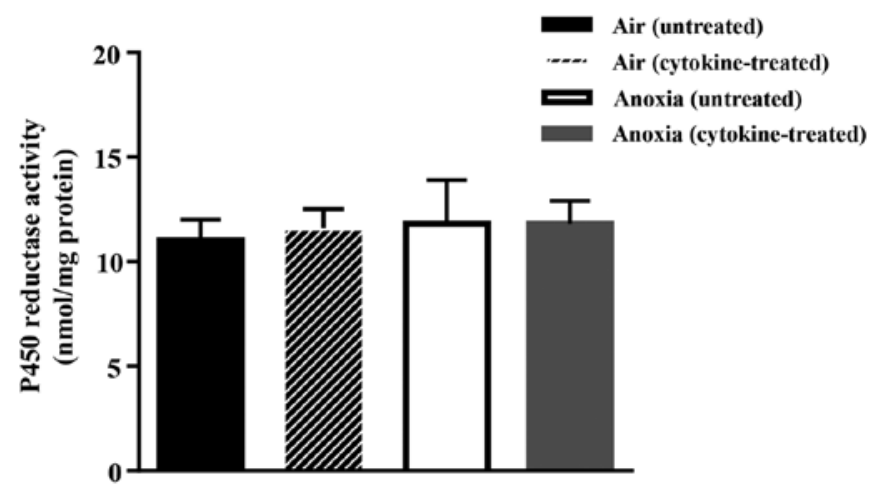

Figure 2. Cytochrome P450 reductase levels. Activity measured in untreated and cytokine treated HT1080 cells in normoxic and anoxic conditions. Columns, average from at least three independent experiments; bars, SD.

containing the iNOS inhibitor NMLA to preclude any contribution to toxicity by NO. Cytotoxicity was then measured using clonogenic survival assay and the data are presented in Fig. 3A-C.

The normoxic $\mathrm{IC}_{10}$ value of AQ4N $(12.4 \mu \mathrm{M})$ in HT1080 parental cells did not significantly change following induction with cytokines or transfection with the iNOS gene $(\sim 9 \mu \mathrm{M}$ in both cell lines). In fact, sensitivity of the three cell lines to AQ4N was dependent on both hypoxia and the level of iNOS activity with HT1080 iNOS $_{12}$ cells exhibiting the highest sensitivity to the drug under conditions of hypoxia and this corresponds to the higher level of iNOS activity in these cells.

For example, under conditions of $1 \%$ oxygen, there was a 1.3-fold decrease in the $\mathrm{IC}_{10}$ value of HT1080 parental cells, a 2.7-fold decrease in the $\mathrm{IC}_{10}$ value of cytokine-induced cells and a 3.4-fold decrease in the $\mathrm{IC}_{10}$ value of HT1080 $\mathrm{iNOS}_{12}$ cells in comparison to their corresponding normoxic $\mathrm{IC}_{10}$ values. Under more severe hypoxic conditions $(0.1 \%$ oxygen level), there was a 1.9-, 4.7- and 7.1-fold increase in AQ4N cytotoxicity in HT1080 parental, cytokine-induced cells and HT1080 iNOS $_{12}$ cells, respectively. In anoxia, these values further increased to 2, 5.1 and 10.9 in each of the cell lines.

Radiation enhances the chemotherapeutic effects of $A Q 4 N$ in iNOS-expressing cell lines. The effect of a low radiation dose ( 2 Gy) on the cellular toxicity of AQ4N was examined in 
A

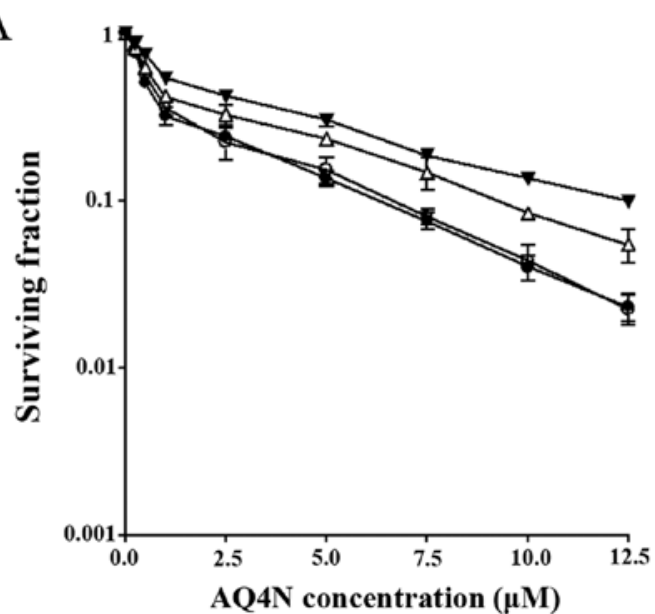

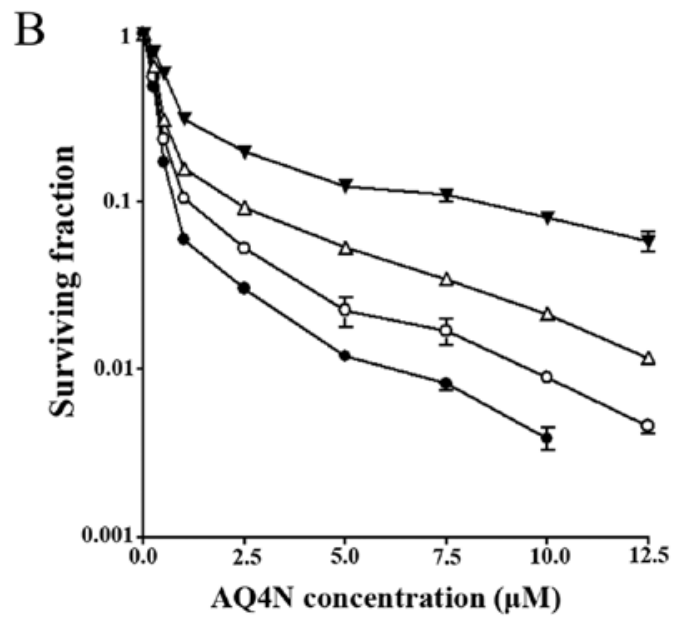

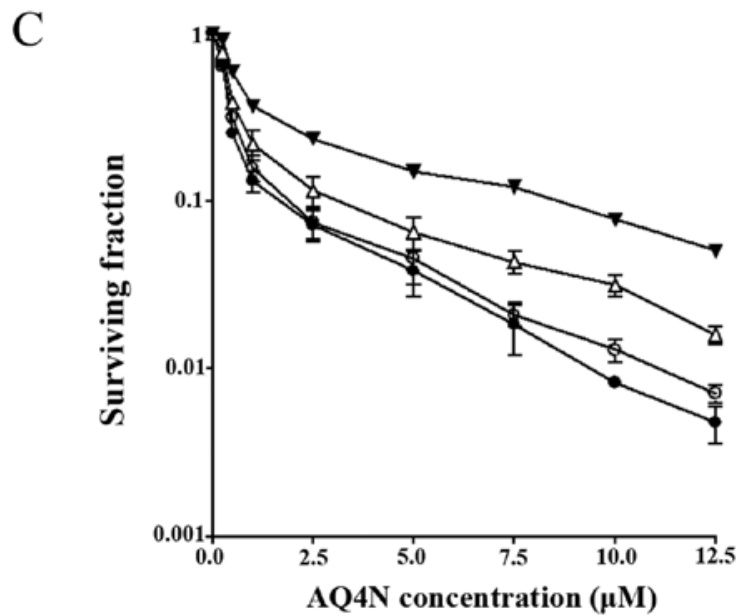

Figure 3. Clonogenic survival curves showing the sensitivity of (A) HT1080 parental cells and (B) HT1080-iNOS ${ }_{12}$ clones. (C) LPS + IFN- $\gamma$ treated HT1080 cells (with NMLA) to AQ4N. Symbols are for cells in anoxia $(\bullet), 0.1 \%$ oxygen (O), $1 \%$ oxygen $(\Delta)$ and $21 \%$ oxygen $(\mathbf{v})$. Data represent the surviving fraction relative to that of untreated cells. Points, average from at least three independent experiments; bars, SD.

the two cell lines expressing different levels of iNOS activity: HT1080 iNOS $_{12}$ and cytokine-induced HT1080 cells. NMLA was also present in the cultures during the course of these experiments to exclude any contribution by NO.

We found that cytotoxicity of AQ4N was enhanced by radiation in both cell lines when compared to exposure to the drug alone. This enhancement was significant only under anoxic and hypoxic conditions (Fig. 4). The drug dose required to achieve $10 \%$ survival of $\mathrm{HT} 1080 \mathrm{iNOS}_{12}$ cells in anoxia was $0.75 \mu \mathrm{M}$. However, when the cells were exposed to a radiation dose of 2 Gy immediately after AQ4N treatment, the dose required to achieve $10 \%$ cell survival was further reduced to $0.38 \mu \mathrm{M}$, representing a 2-fold enhancement in cytotoxicity of AQ4N. Under $0.1 \%$ oxygen conditions, $1.15 \mu \mathrm{M}$ of $\mathrm{AQ} 4 \mathrm{~N}$ was required to achieve $10 \%$ cell survival, whereas, when AQ4N was combined with radiation, the drug concentration required fell to $0.55 \mu \mathrm{M}$, leading to another 2-fold increase in toxicity of the prodrug. Again, under $1 \%$ oxygen conditions, radiation led to a 1.8-fold increase in sensitivity of the cells to AQ4N (Fig. 4A).

A similar pattern was observed with the cytokine-treated cells, although higher drug concentrations were required to achieve similar results which could be explained by their lower ability to activate AQ4N. For example, under anoxic conditions, $1.68 \mu \mathrm{M}$ of $\mathrm{AQ} 4 \mathrm{~N}$ was required to achieve $10 \%$ survival in anoxia, which further decreased to $0.75 \mu \mathrm{M}$ when the cells were exposed to radiation, leading to a 2.2-fold enhancement in drug toxicity. In $1 \%$ oxygen conditions, a concentration of $3.2 \mu \mathrm{M}$ of AQ4N was needed to achieve $10 \%$ cell survival, and this requirement was again reduced to $1.6 \mu \mathrm{M}$ after irradiation, representing a 2-fold enhancement (Fig. 4B).

$N O$ enhances the radiosensitising effects of $A Q 4 N$. The effect of endogenously produced $\mathrm{NO}$ on the sensitivity of cells to the combination therapy of radiation $(2 \mathrm{~Gy})$ and AQ4N was assessed in HT1080 iNOS $_{12}$ clones and cytokine-induced HT1080 cells. We demonstrated that AQ4N was most potent when NO release was allowed prior to irradiation. The results suggest that this increase in potency is due to the NO-mediated 'fixing' of the radiation-induced damage which was observed in intermediate oxygen conditions only. There was a 1.4- and 2.2-fold increase in sensitivity of HT1080 iNOS $_{12}$ cells to AQ4N/radiation treatment when NO was present under conditions of $0.1 \%$ and $1 \%$ oxygen, respectively (Fig. 5A). Therefore, compared to the drug alone, 2.8- and 5.26-fold enhancement in AQ4N sensitisation was achieved with 

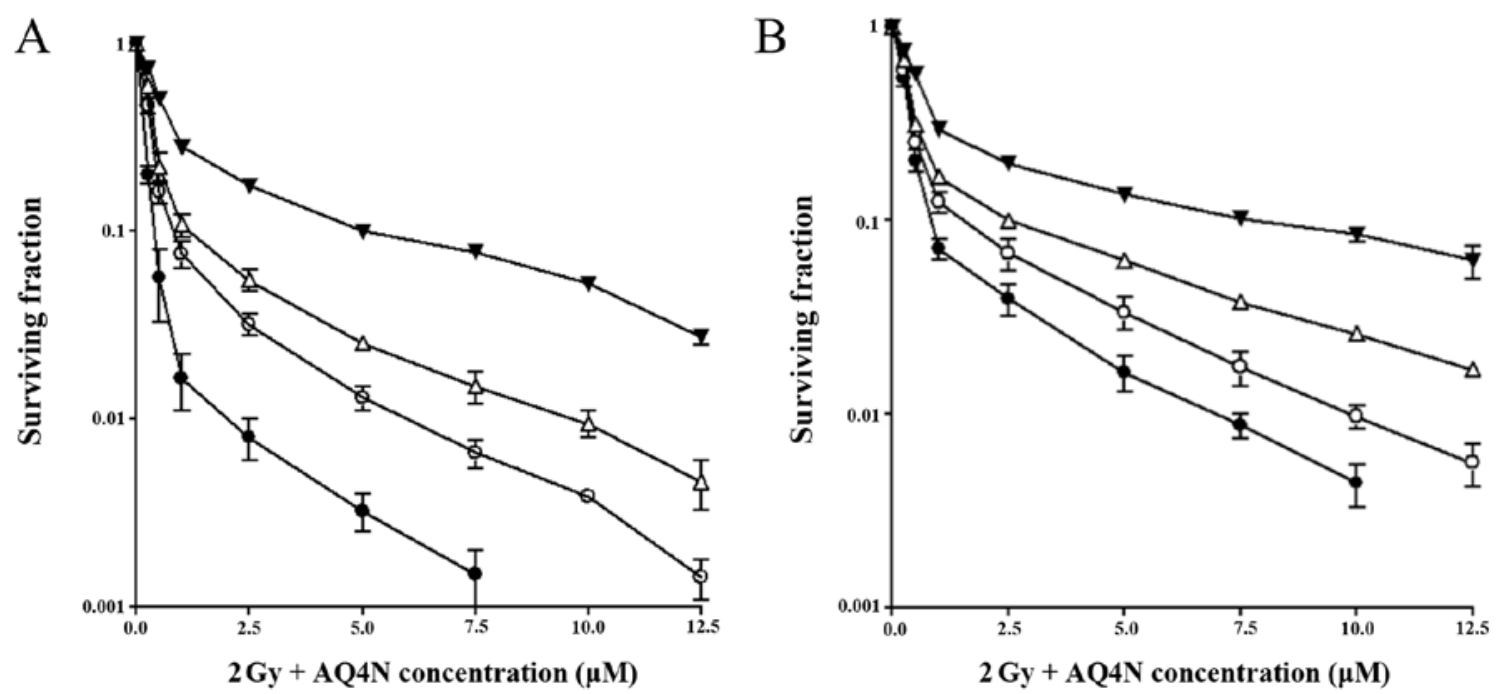

Figure 4. Clonogenic survival curves showing the effect of 2 Gy radiation dose on the sensitivity of (A) HT1080 iNOS I $_{12}$ clones (B) LPS + IFN- $\gamma$ treated HT1080 cells to AQ4N in the presence of NMLA. Symbols are for cells in anoxia $(\bullet), 0.1 \%$ oxygen $(0), 1 \%$ oxygen $(\Delta)$ and $21 \%$ oxygen $(\mathbf{v})$. Data represent the surviving fraction relative to that of untreated cells. Points, average from at least three independent experiments; bars, SD.

combination therapy of $\mathrm{AQ} 4 \mathrm{~N} /$ radiation/ $\mathrm{NO}$ under $0.1 \%$ and $1 \%$ oxygenation levels, respectively.

This effect was comparable in HT1080 cytokine-induced cells (Fig. 5B). The sensitisation enhancement ratios for NO were 1.41 and 2.13 in 0.1 and $1 \%$ oxygen levels, respectively. Therefore, combination therapy of AQ4N/radiation/NO resulted in up to 4 -fold increase in cell sensitisation when compared to $\mathrm{AQ} 4 \mathrm{~N}$ monotherapy under hypoxic conditions.

Evidence for the involvement of $\mathrm{NO}$ in this enhancement was provided by the addition of the NO inhibitor NMLA, which completely reversed the previously observed effect. As expected, no enhancement in cellular toxicity of either cell line was observed in anoxia since NO production is very limited. In addition, under normoxic conditions, iNOS expression and subsequent production of NO did not have any additive effect to oxygen in radiosensitisation of the cells.

\section{Discussion}

AQ4N is an attractive hypoxia-activated prodrug since it penetrates deep into tumour tissue (29), and its final toxic metabolite AQ4 is stable and generally localises to the hypoxic tumour regions as shown in both pre-clinical and clinical studies $(10,30)$. However, its cytotoxicity is disadvantaged by the limited in vitro bioactivation in several cancer cell lines incubated under hypoxic conditions (31). In fact, significant cytotoxicity of AQ4N was only observed when hypoxic cells were incubated with NADPH supplemented microsomes (32). Although, enzymes such as cytochrome $\mathrm{P} 450$ reductases are useful in activating bioreductive prodrugs in human cell cultures, their expression in tumours tend to be low and generally does not overlap with biomarkers of hypoxia such as carbonic anhydrase IX (33). Therefore, our aim here was to mimic an in vivo situation where enzymatic activity is abundant. We chose nitric oxide (NO) synthase since the enzyme is widely expressed and often upregulated in multiple tumour tissues with an expression that correlates with tumour grade, high incidence of metastasis and poor prognosis (18,19,34-37). Immunohistochemical staining of breast tumour biopsies revealed that the expression of the NOS enzyme was mainly localised in areas between viable and necrotic regions of the tumour (presumably hypoxic regions) (25). Therefore, considerable benefit could be gained by exploiting the inherent differences in NOS expression that can distinguish between normal and malignant tissues as well as its ability to produce a hypoxic cytotoxin and generate the strong radiosensitiser NO.

We initially examined the ability of iNOS to activate AQ4N and improve its toxicity in vitro in the human fibrosarcoma cells HT1080. AQ4N was shown to produce an oxygen-dependent effect as there was a clear difference in clonogenic cell kill between normoxic and hypoxic conditions with the greatest cell kill occurring in anoxia. AQ4N treatment targeted to the iNOS expressing cells led to further reductions in the drug dose required to achieve similar toxicity under all oxygen concentrations except normoxia. Our results are in agreement with the fact that both enzymatic activity and hypoxia are pre-requisites for the efficient activation of AQ4N (12).

Combination therapy of AQ4N and radiation experiments demonstrate that enhancement of cytotoxicity was only observed in hypoxia without affecting well-oxygenated tissues. Therefore, combining the two therapeutic agents can increase toxicity to the hypoxic tumour cells without doing so in the critical normal tissues.

Although the role of NO as a radiosensitiser was first reported in hypoxic bacteria and human cells not long after oxygen $(23,38)$, it was not until recently that its potential radiosensitising properties have been rediscovered with the development of several NO-generating agents. These compounds showed that NO was almost as efficient as oxygen in improving the radiosensitivity of cancer cells (39-41). In the present study, we found that NO exhibited important cell-sensitisation characteristics to the combination of AQ4N and radiotherapy under hypoxic conditions. The fact that this 

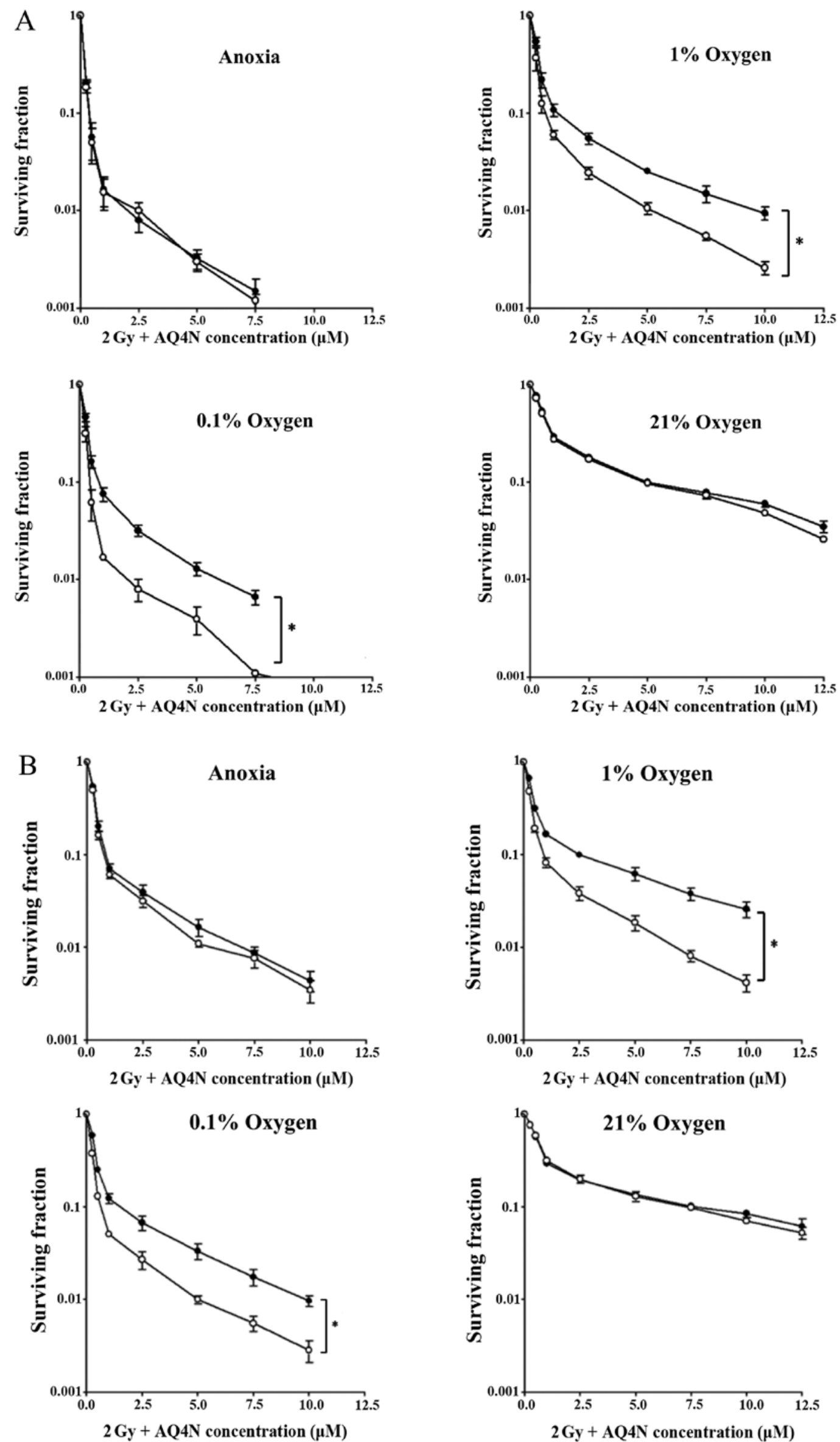

Figure 5. Clonogenic survival curves showing the effect of 2 Gy radiation dose on the sensitivity of (A) HT1080 iNOS $_{12}$ clones (B) LPS + IFN- $\gamma$ treated HT1080 cells to AQ4N in the presence (•) and absence (O) of NMLA. Conditions tested anoxia, $0.1 \%, 1 \%$ and $21 \%$ oxygen. Data represent the surviving fraction relative to that of untreated cells. Points, average from at least three independent experiments; bars, SD. "P<0.05. 
enhancement was abolished by an iNOS inhibitor confirms the role of NO in mediating this effect. Under normoxic conditions, we believe that oxygen on its own is able to mediate maximal radiation-induced damage, hence, masking any radiosensitising effects of NO (24). Using different oxygen conditions to model the varied oxygenation level usually found in tumour tissues, we were able to examine not only the cytotoxicity effects under different oxygen concentrations, but more importantly the changes in the level of radiosensitivity when NO was generated endogenously.

Obviously, rationale design of novel bioreductive drugs based on knowledge of their enzymology and heterogeneity of the tumour microenvironment is a vital approach in the development of anticancer therapeutics. Importantly, identifying a clinical cohort that is most likely to benefit from these prodrugs is essential in ensuring their success in the clinic. In the present study, we demonstrate that increased iNOS expression in hypoxic tumour cells presents a viable target to improve treatment outcomes with $\mathrm{AQ} 4 \mathrm{~N}$ and radiation without sensitising the healthy well-oxygenated tissues. Hopefully, lessons will be learned from previous failures of bioreductive drugs in clinical trials and a more personalised therapy approach will be adopted in the future.

\section{Acknowledgements}

The present study was supported by grant from the KuDOS Pharmaceuticals Ltd. (now AstraZeneca) to I.J.S., the Medical Research Council (I.J.S. and K.J.W.), and the EU 6th and 7th Framework Programmes Euroxy (I.J.S.) and Metoxia (K.J.W.) respectively, and are gratefully acknowledged.

\section{References}

1. Brown JM: Exploiting the hypoxic cancer cell: Mechanisms and therapeutic strategies. Mol Med Today 6: 157-162, 2000.

2. Hockel M, Schlenger K, Aral B, Mitze M, Schaffer U and Vaupel P: Association between tumor hypoxia and malignant progression in advanced cancer of the uterine cervix. Cancer Res 56: 4509-4515, 1996.

3. Brizel DM, Sibley GS, Prosnitz LR, Scher RL and Dewhirst MW: Tumor hypoxia adversely affects the prognosis of carcinoma of the head and neck. Int J Radiat Oncol Biol Phys 38: 285-289, 1997.

4. Ning S, Bednarski M, Oronsky B, Scicinski J, Saul G and Knox SJ: Dinitroazetidines are a novel class of anticancer agents and hypoxia-activated radiation sensitizers developed from highly energetic materials. Cancer Res 72: 2600-2608, 2012.

5. Hicks KO, Siim BG, Jaiswal JK, Pruijn FB, Fraser AM, Patel R, Hogg A, Liyanage HD, Dorie MJ, Brown JM, et al: Pharmacokinetic/pharmacodynamic modeling identifies SN30000 and SN29751 as tirapazamine analogues with improved tissue penetration and hypoxic cell killing in tumors. Clin Cancer Res 16: 4946-4957, 2010.

6. Smith P: Cytomics of the tumour microenvironment: Therapeutic targeting. J Inflamm 12 (Suppl 1): O10, 2015.

7. McKeown SR, Cowen RL and Williams KJ: Bioreductive drugs: From concept to clinic. Clin Oncol (R Coll Radiol) 19: 427-442, 2007.

8. Mehibel M, Singh S, Chinje EC, Cowen RL and Stratford IJ: Effects of cytokine-induced macrophages on the response of tumor cells to banoxantrone (AQ4N). Mol Cancer Ther 8: 1261-1269, 2009.

9. McKeown SR, Hejmadi MV, McIntyre IA, McAleer JJ and Patterson LH: AQ4N: An alkylaminoanthraquinone N-oxide showing bioreductive potential and positive interaction with radiation in vivo. Br J Cancer 72: 76-81, 1995.
10. Williams KJ, Albertella MR, Fitzpatrick B, Loadman PM, Shnyder SD, Chinje EC, Telfer BA, Dunk CR, Harris PA and Stratford IJ: In vivo activation of the hypoxia-targeted cytotoxin AQ4N in human tumor xenografts. Mol Cancer Ther 8: 3266-3275, 2009.

11. Friery OP, Gallagher R, Murray MM, Hughes CM, Galligan ES, McIntyre IA, Patterson LH, Hirst DG and McKeown SR: Enhancement of the anti-tumour effect of cyclophosphamide by the bioreductive drugs $\mathrm{AQ} 4 \mathrm{~N}$ and tirapazamine. $\mathrm{Br} \mathrm{J}$ Cancer 82 : 1469-1473, 2000.

12. Patterson LH and McKeown SR: AQ4N: A new approach to hypoxia-activated cancer chemotherapy. Br J Cancer 83: 1589-1593, 2000.

13. McCarthy HO, Yakkundi A, McErlane V, Hughes CM, Keilty G, Murray M, Patterson LH, Hirst DG, McKeown SR and Robson T: Bioreductive GDEPT using cytochrome P450 3A4 in combination with AQ4N. Cancer Gene Ther 10: 40-48, 2003.

14. McErlane V, Yakkundi A, McCarthy HO, Hughes CM, Patterson LH, Hirst DG, Robson T and McKeown SR: A cytochrome P450 2B6 meditated gene therapy strategy to enhance the effects of radiation or cyclophosphamide when combined with the bioreductive drug AQ4N. J Gene Med 7: 851-859, 2005.

15. Rooseboom M, Commandeur JN and Vermeulen NP: Enzymecatalyzed activation of anticancer prodrugs. Pharmacol Rev 56: 53-102, 2004.

16. Nishida CR and Ortiz de Montellano PR: Reductive hemedependent activation of the $N$-oxide prodrug AQ4N by nitric oxide synthase. J Med Chem 51: 5118-5120, 2008.

17. Fitzpatrick B, Mehibel M, Cowen RL and Stratford IJ: iNOS as a therapeutic target for treatment of human tumors. Nitric Oxide 19: 217-224, 2008.

18. Cobbs CS, Brenman JE, Aldape KD, Bredt DS and Israel MA: Expression of nitric oxide synthase in human central nervous system tumors. Cancer Res 55: 727-730, 1995.

19. Gallo O, Masini E, Morbidelli L, Franchi A, Fini-Storchi I, Vergari WA and Ziche M: Role of nitric oxide in angiogenesis and tumor progression in head and neck cancer. J Natl Cancer Inst 90: 587-596, 1998.

20. Hemmens B and Mayer B: Enzymology of nitric oxide synthases. Methods Mol Biol 100: 1-32, 1998

21. Bredt DS, Hwang PM, Glatt CE, Lowenstein C, Reed RR and Snyder SH: Cloned and expressed nitric oxide synthase structurally resembles cytochrome P-450 reductase. Nature 351 : 714-718, 1991.

22. Griffith OW and Stuehr DJ: Nitric oxide synthases: Properties and catalytic mechanism. Annu Rev Physiol 57: 707-736, 1995.

23. Gray LH, Green FO and Hawes CA: Effect of nitric oxide on the radiosensitivity of tumour cells. Nature 182: 952-953, 1958.

24. Singh S, Cowen RL, Chinje EC and Stratford IJ: The impact of intracellular generation of nitric oxide on the radiation response of human tumor cells. Radiat Res 171: 572-580, 2009.

25. Chinje EC, Williams KJ, Telfer BA, Wood PJ, van der Kogel AJ and Stratford IJ: 17beta-Oestradiol treatment modulates nitric oxide synthase activity in MDA231 tumour with implications on growth and radiation response. Br J Cancer 86: 136-142, 2002.

26. Chinje EC, Cowen RL, Feng J, Sharma SP, Wind NS, Harris AL and Stratford IJ: Non-nuclear localized human NOSII enhances the bioactivation and toxicity of tirapazamine (SR4233) in vitro. Mol Pharmacol 63: 1248-1255, 2003.

27. Patterson AV, Barham HM, Chinje EC, Adams GE, Harris AL and Stratford IJ: Importance of P450 reductase activity in determining sensitivity of breast tumour cells to the bioreductive drug, tirapazamine (SR 4233). Br J Cancer 72: 1144-1150, 1995.

28. Smith PK, Krohn RI, Hermanson GT, Mallia AK, Gartner FH, Provenzano MD, Fujimoto EK, Goeke NM, Olson BJ and Klenk DC: Measurement of protein using bicinchoninic acid. Anal Biochem 150: 76-85, 1985.

29. Trédan O, Garbens AB, Lalani AS and Tannock IF: The hypoxiaactivated ProDrug AQ4N penetrates deeply in tumor tissues and complements the limited distribution of mitoxantrone. Cancer Res 69: 940-947, 2009.

30. Albertella MR, Loadman PM, Jones PH, Phillips RM, Rampling R, Burnet N, Alcock C, Anthoney A, Vjaters E, Dunk CR, et al: Hypoxia-selective targeting by the bioreductive prodrug AQ4N in patients with solid tumors: Results of a phase I study. Clin Cancer Res 14: 1096-1104, 2008.

31. Manley E Jr and Waxman DJ: Impact of tumor blood flow modulation on tumor sensitivity to the bioreductive drug banoxantrone. J Pharmacol Exp Ther 344: 368-377, 2013. 
32. Patterson LH: Rationale for the use of aliphatic $\mathrm{N}$-oxides of cytotoxic anthraquinones as prodrug DNA binding agents: A new class of bioreductive agent. Cancer Metastasis Rev 12: 119-134, 1993.

33. Guise CP, Abbattista MR, Tipparaju SR, Lambie NK, Su J, Li D, Wilson WR, Dachs GU and Patterson AV: Diflavin oxidoreductases activate the bioreductive prodrug PR-104A under hypoxia. Mol Pharmacol 81: 31-40, 2012.

34. Swana HS, Smith SD, Perrotta PL, Saito N, Wheeler MA and Weiss RM: Inducible nitric oxide synthase with transitional cell carcinoma of the bladder. J Urol 161: 630-634, 1999.

35. Song ZJ, Gong P and Wu YE: Relationship between the expression of iNOS, VEGF, tumor angiogenesis and gastric cancer. World J Gastroenterol 8: 591-595, 2002.

36. Lagares-Garcia JA, Moore RA, Collier B, Heggere M, Diaz F and Qian F: Nitric oxide synthase as a marker in colorectal carcinoma. Am Surg 67: 709-713, 2001.
37. Thomsen LL, Miles DW, Happerfield L, Bobrow LG, Knowles RG and Moncada S: Nitric oxide synthase activity in human breast cancer. Br J Cancer 72: 41-44, 1995.

38. Howard-Flanders P: Effect of nitric oxide on the radiosensitivity of bacteria. Nature 180: 1191-1192, 1957.

39. Griffin RJ, Makepeace CM, Hur WJ and Song CW: Radiosensitization of hypoxic tumor cells in vitro by nitric oxide. Int $\mathrm{J}$ Radiat Oncol Biol Phys 36: 377-383, 1996.

40. Mitchell JB, Cook JA, Krishna MC, DeGraff W, Gamson J, Fisher J, Christodoulou D and Wink DA: Radiation sensitisation by nitric oxide releasing agents. Br J Cancer Suppl 27: S181-S184, 1996.

41. Verovski VN, Van den Berge DL, Soete GA, Bols BL and Storme GA: Intrinsic radiosensitivity of human pancreatic tumour cells and the radiosensitising potency of the nitric oxide donor sodium nitroprusside. Br J Cancer 74: 1734-1742, 1996. 